\title{
The doctor-patient relationship during the COVID-19 pandemic. A point of view
}

\author{
La relación médico paciente durante la pandemia de COVID-19. Un punto de vista
}

Jorge Álvarez de-la-Cadena

Department of Cardiology, Instituto de Corazón de Querétaro, Querétaro, Mexico

Dear Editor,

From the beginning of medical practice, it has always been emphasized on the value of the clinical interview for an accurate development of good praxis. This first contact between the doctor and patient is the beginning of a doctor/patient relationship. This initial relationship based on warmth and empathy can draw the beginning of non-pharmaceutical treatment. The sick pours all his confidence on the person who is in front, if the doctor has achieved a nonverbal understanding between them. This will provide of that healing hope and certainty that he will know how to best treat him. How often do we hear the expression "Oh Doctor, just the site of you makes me feel better!"'.

This process that is as real as it is romantic, has now been modified with the presence of severe acute respiratory syndrome coronavirus 2 . We now have limited any physical contact, may it be a hug or a handshake, for there is the underlying fear of transmission of an enemy from which we know certain characteristic, but still not enough. The uncertainty that comes with knowing the wide range of clinical manifestations that can be from completely asymptomatic all the way to severe respiratory distress, systemic intravascular coagulation, and death. Its high transmission capacity along with the fear of acquiring the disease not only at home or public places but also in the medical office or hospitals, has limited the doctor/patient relationship. Us doctors have little by little learned about its physiopathology and hence its treatment. However, we hardly imagined the consequences this high risk infectious transmission will bring into our daily life, being our professional life the most affected, specifically when this doctor/patient relationship is not nurtured by this initial physical and humane contact that we have mentioned ${ }^{2}$.

The high transmission of this virus has driven to the isolation of contagious patients, not only from other patients but also from all medical personnel, family, and loved ones. This drives them to mourn the sickness itself. Creating added mental stress and loneliness. Health personnel that could otherwise help mitigate this situation through empathy are now forced to respect strict isolation protocols and wear personal protection equipment that sets further another barrier upon this already undermined doctor/patient relationship. This isolation is now physical and also sensorial thus limiting the nonverbal communication that is essential through facial expressions that could transmit optimism or reassuring physical gestures. The doctors glance that in other occasions could have been reassuring, is now masked behind medical protection equipment, and is now veiling the fear of personally acquiring the virus ${ }^{3}$.

All these new barriers that all medical personnel are confronted with, especially nurses and doctors, translate into distancing from the patient, with absence of not only physical contact but also verbal communication with the difficulty to listen through the masks. Corporal expression, another nonverbal

\section{Correspondence:}

*Jorge Álvarez de-la-Cadena

E-mail: jalvarezdelacadena@gmail.com DOI: $10.24875 /$ ACM.21000114 license (http://creativecommons.org/licenses/by-nc-nd/4.0/)
Date of reception: 09-04-2021

Date of acceptance: 21-05-2021

Available online: 17-06-2021 Arch Cardiol Mex. 2021;91(Supl):138-139 www.archivoscardiologia.com
article under the CC BY-NC-ND 
communication is also hindered. We are now forced to look for other forms of empathizing with the patient since we now lack of the closeness physical contact give. If we can achieve these alternative ways of contact it will enable us to restore empathy and trust, it will allow us to share pain, Of course, and sometimes this contact is also used to bear bad news. Sometimes it is necessary when we want to comfort in case we want to inform of bad outcomes or death. Nonverbal expression is also important when we want to transmit our feelings, knowledge, and expertise to our family and friends that are living through the viral disease themselves or accompanying members of the family. Having themselves to live through this same frustration, when all these barriers are encountered limiting a complete communication ${ }^{4}$.

I have always said that one of the most rewarding situations in my profession is to be able to follow and share up to the last breath of life with my patients. This upmost privilege that not every human being has is now covered with sadness and frustration that is exponentially incremented by the isolation and loneliness the patient has to suffer, being at the end solitude his only companion.

At this very moment, we require of empathy, comprehension, and help from our government and society. It is fundamental that we weigh the absolute importance of the obligatory use of face mask implemented by other countries already. Specific vaccination will help; however, it will no set an end to this pandemic event. We require to modify our hygiene habits and conducts, adapt to the new circumstances so we may practice our profession as it was once conceived, based on an authentic doctor/patient humane relationship, using the full context of the word.

\section{Acknowledgments}

The authors would like to thank Enrique Asensio Lafuente, MD, and Lillian Hernandez Garcia, MD, for the contribution reviewing and translating the text.

\section{Funding}

None.

\section{Conflicts of interest}

None.

\section{Ethical disclosures}

Protection of human and animal subjects. The authors declare that no experiments were performed on humans or animals for this study.

Confidentiality of data. The authors declare that no patient data appear in this article.

Right to privacy and informed consent. The authors declare that no patient data appear in this article.

\section{References}

1. Vallelonga F, Elia F. Doctor-patient relationship at the time of Covid-19 travel notes. Intensive Care Med. 2020;46:1802.

2. Back A, Tulsky JA, Arnold RM. Comunication skills in the age of Covid-19. Ann Inter Med. 2020;172:759-60.

3. Gao B, Dong J. Does the impact of Covid-19 improve the doctor-patient relationship in China? Am J Med Sci. 2020;360:305-6.

4. Cunningham CO, Diaz C, Slawek DE. Covid 19: the worst days of our carreers. Ann Inter Med. 2020;172:764-5. 